\title{
Integration of risk and uncertainty on levelized cost of electricity calculation
}

\author{
Jorge Cunha ${ }^{1}(\varangle)$ and Paula Ferreira ${ }^{1}$ \\ ${ }^{1}$ ALGORITMI Research Center, University of Minho, Portugal \\ jscunha@dps.uminho.pt paulaf@dps.uminho.pt
}

\begin{abstract}
The electric sector is still largely dependent on non-renewable energy sources. The importance of using renewable energies is increasingly recognized all across the world yet they are not fully ready to compete with the mature and ancient technologies that use non-renewable energies. The economic characteristics of different energy technologies can be compared by using the method of levelized cost of electricity (LCOE). LCOE represents the total cost of a power plant including investment and operation and maintenance costs over the assumed life-cycle and discounted to account for the time-value of money. In this paper, an analysis of the levelized costs is proposed for two renewable technologies in Portugal: wind power and solar photovoltaic. Firstly, a deterministic value of LCOE was computed for both technologies. Secondly, recognizing the uncertainty associated with all the assumed parameters, a probabilistic risk analysis was conducted with Monte Carlo simulation to complement the analysis. The results show the high variability of the obtained LCOE values, largely influenced by the investment values and load factors.
\end{abstract}

Keywords: Levelized cost of electricity (LCOE); probabilistic risk analysis; Renewable energy sources

\section{Introduction}

Electricity plays an important role for the achievement of sustainable development of countries with major impacts on the state of the environment and the climate. However, fossil fuels and nuclear are the energy sources that still dominate electricity production in most countries [1]. Notwithstanding, the European Union is focused on changing this situation [2] and the use of renewable energy sources (RES) for electricity generation is seen as the sustainable future that will help leave a better world for future generations. However, these poses some challenges since the integration of variable renewable energy based electricity production, like wind and solar for example, is estimated to be costlier than non-variable resources, given the required flexibility of the system to respond to RES intermittency. To assess the generation costs of electricity from different technologies, the levelized cost of electricity (LCOE) financial model has been used [3]. It calculates the typical levelized costs of generating electricity over

adfa, p. 1, 2011.

(C) Springer-Verlag Berlin Heidelberg 2011 
the entire operating life of the power plant for a given technology [4], taking into account key cost components, such as capital costs, fuel costs and operations and maintenance (O\&M) costs [5]. Moreover, this analytical framework allows precise cost factors, such as contingency, decommissioning and carbon prices to be considered. LCOE can be interpreted as the price that must be received per unit of output as payment for producing power in order to reach a pre-defined financial return [6], or, in other words, the price that project must earn per megawatt hour in order to break-even. The LCOE calculation normalizes the units of measuring the lifecycle costs of producing electricity, thus facilitating the comparison of the cost of producing one megawatt hour by each technology [7]. Since the LCOE reveal the main cost factors of alternative generation options, and as long as many cost components vary extensively from location to location and project to project, sensitivity analyses may be performed to evaluate the impact of changes in key parameters on the costs of generating electricity. Thus, LCOE can assess the costs of producing electricity from a new power plant or for a given technology and evaluating the numerous generation options presented to investors in a given market. Therefore, LCOE can be used as a benchmarking or ranking tool to assess the cost-effectiveness of different energy generation technologies [8], resulting on an important tool for policy makers in figuring out the main cost drivers of an electricity system and in evaluating the importance of policies for generation costs. Investment projects would be better analyzed by associating LCOE with a more comprehensive risk analysis, in which multiple risks are taken into account. In fact, the uncertainty surrounding RES is still high given the possibility of technologies development and even due to the uncertainty of climate conditions which affect the underlying RES resources such as wind, solar intensity or rainfall.

Given this context, this paper aims to make a contribution to the assessment and integration of risk and uncertainty on LCOE calculation, presenting a probabilistic risk analysis of these values. Given the availability of data and the importance of both wind and solar power for the future of the Portuguese electricity system, both solar photovoltaic (PV) and wind power were selected for the study.

\section{LCOE for wind and solar PV in Portugal}

In order to determine the LCOE of wind onshore and solar PV, the following Equation (1) was used:

$\mathrm{LCOE}=\mathrm{P}_{\text {Electricity }}=\frac{\sum_{t=1}^{N}\left(\text { Investment }_{\mathrm{t}}+\mathrm{O} \& \mathrm{M}_{\mathrm{t}}+\text { Decommissioning }_{\mathrm{t}}\right)(1+\mathrm{r})^{-\mathrm{t}}}{\sum_{t=1}^{N} \text { Electricity }_{\mathrm{t}}(1+\mathrm{r})^{-\mathrm{t}}}$

where Electricityt: amount of electricity produced in year " $t$ "; $P_{\text {Electricity: required elec- }}$ tricity price over the life time of the power plant to cover all costs; : discount rate; $\mathrm{N}$ : life time of the plant; Investment: investment in year " $\mathrm{t}$ "; O\& $\mathrm{M}_{\mathrm{t}}$ : operations and maintenance costs in year " $\mathrm{t}$ "; Decommissioningt: decommissioning cost in year " $\mathrm{t}$ ".

For the calculations of the LCOE, the following assumptions were made. Firstly, installation of a $10 \mathrm{MW}$ onshore wind and a $2 \mathrm{MW}$ solar PV power plants. Secondly, theoretical operating time of 8,760 hours in a year. Thirdly, data for investment, O\&M 
and decommissioning costs for both wind and solar technologies were collected from [9]. Fourthly, the expected power output and the corresponding load factor for both technologies were obtained from [10] and [11]. The historical values since 1998 were used allowing assessing the variability of these resources. Fifthly, for this type of investments, the literature tends to assign values of 5 or $10 \%$ to the discount rate (NEA, 2015). In this study, a rate of 5\% was used. Finally, after the collection of the values of electricity generation and installed power, for both solar PV and wind onshore, from year 1998 to 2015 in Portugal, the average load factor, LF, of each technology, for each year was estimated using Equation (2).

$$
\mathrm{LF}=\text { Electricity production / (Installed power } * 8,760)
$$

Under a deterministic approach, the average values of investment and O\&M costs, and load factor are usually considered. However, this approach fails to recognize the uncertainty associated with these parameters driven by technological and climatic changes. Therefore, a risk analysis, where multiple risk factors are taken into account, should be pursued based on the probabilistic assessment of the assumed values for costs and load factor parameters for both technologies. This analysis provides very important information for both energy policy decision-makers and investors operating in the electricity production market. In order to conduct the statistical analysis and the probabilistic risk assessment, the software @ Risk was used, since it allows to perform a risk analysis using Monte Carlo simulation showing the several possible outcomes in the spreadsheet model, as well as the likelihood of their occurrence. Notwithstanding the distribution fitting of data series undertaken, a suitable probability distribution function (PDF) for the investment and O\&M costs of wind onshore and for the investment and $\mathrm{O} \& \mathrm{M}$ costs and load factor of solar PV could not be found. For this reason and because of the existence of few data, a triangular distribution was considered. This type of distribution is determined by the maximum, the minimum and the mode. In the case of wind, a normal distribution was assumed based on the mean and the standard deviation for the load factor. Figures 1 to 3 represent the data series and the assigned PDF.
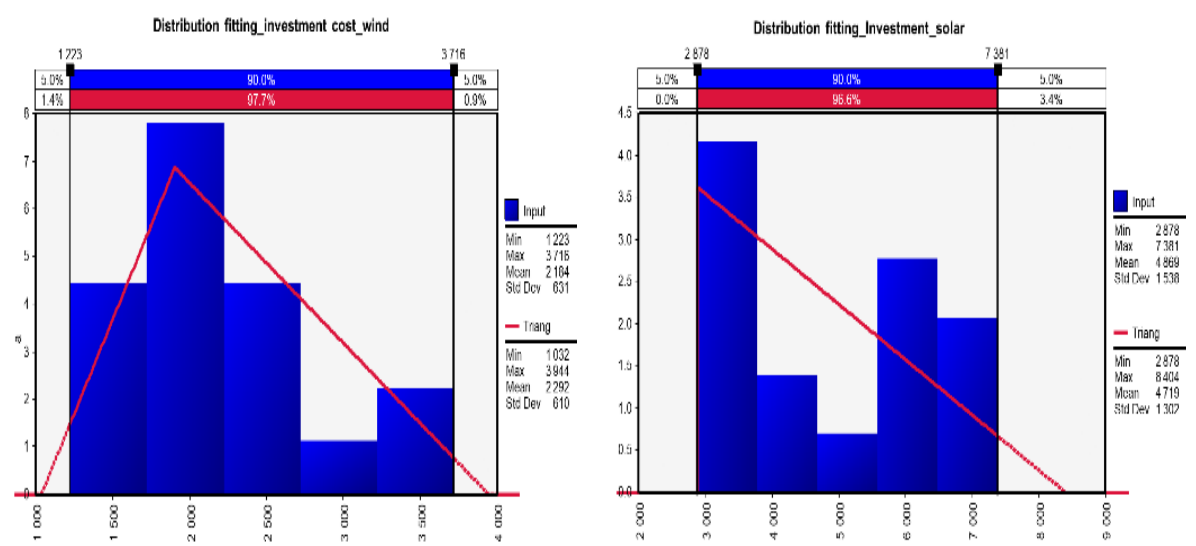

Fig. 1. Distribution fitting for the investment costs of wind and solar PV, respectively. 

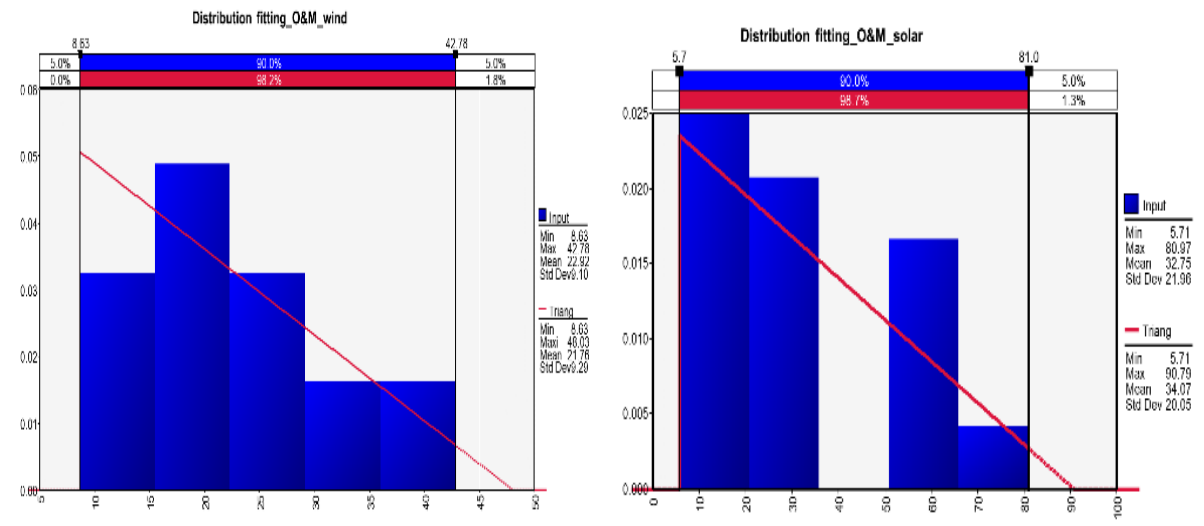

Fig. 2. Distribution fitting for the O\&M of wind and solar PV, respectively.
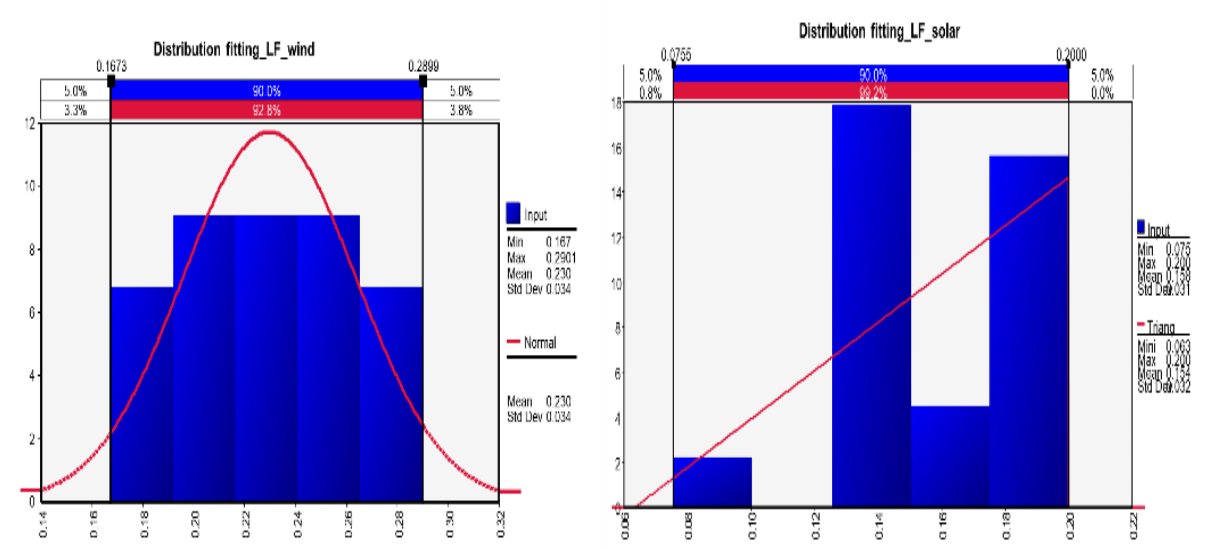

Fig. 3. Distribution fitting for the Load Factor of Wind and solar PV, respectively.

The statistical parameters for each one of the PDF for the risk parameters for both wind and solar PV were used for the combined risk analysis of the LCOE as described in the next section.

\section{$3 \quad$ Risk analysis}

The risk analysis is based on a Monte Carlo simulation combining the main sources of risk and in order to obtain the probabilistic distribution of the LCOE for both wind and solar power technologies in Portugal. Figure 4 shows the obtained PDF function for the LCOE for wind onshore, combining the risk effect on investment cost, O\&M cost and load factor, as well as the tornado chart for the probabilistic sensitivity analysis. 

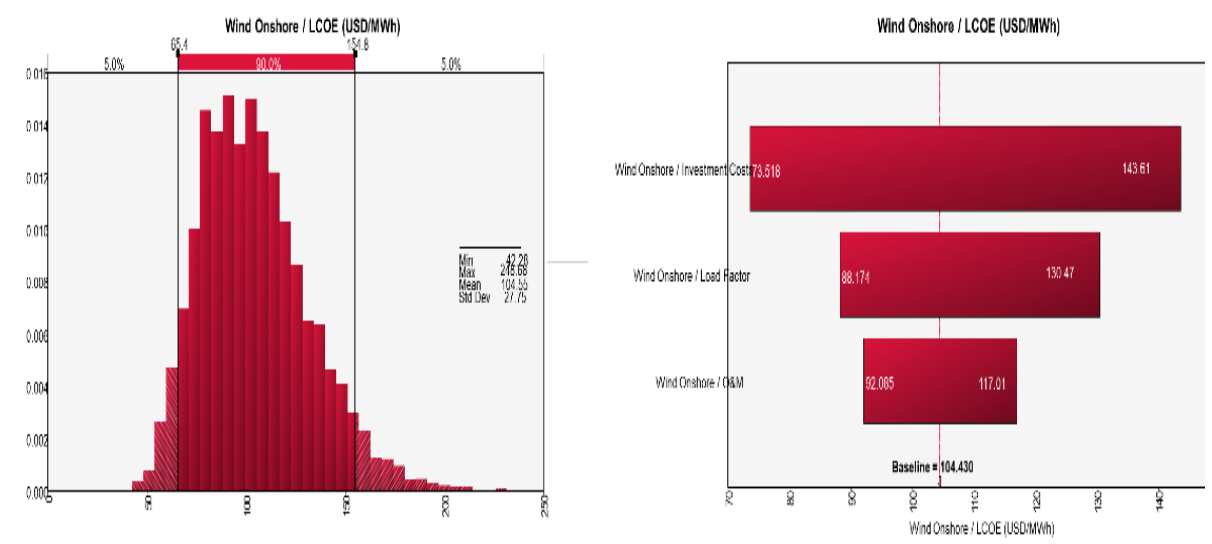

Fig. 4. Probability distribution function (left) and tornado chart (right) for LCOE wind onshore.

According to the previously presented deterministic analysis, LCOE for wind power should be slightly less than $103 \mathrm{USD} / \mathrm{MWh}(93 € / \mathrm{MWh}$, according to average exchange rate in March 2015, from www.bportugal.pt consulted in April 2016). However, Figure 4 shows that the probability of reaching a value higher than this one is more than $50 \%$, thus posing important challenges for investors. This is particularly relevant as average feed-in-tariffs (FIT) for wind power in Portugal were until recently approximately 75 $€ / M W h$ (data obtained from www.dgeg.pt consulted in April 2016), a value much lower than the obtained mean. In fact, the probability of reaching a LCOE value much lower than the FIT is less than 15\%. The tornado chart, also shown in Figure 4, demonstrates the relative importance of each one of the simulated parameters, showing that the investment cost has a major role on the final value of the LCOE. This demonstrates the importance of looking for technology development or scale economies as under the best conditions the LCOE would only be slightly higher than $67 € / \mathrm{MWh}$, with high impact on the investment profitability. The impact of the load factor is also highly relevant and the development of wind evaluation and forecasting models should have a high contribution on ensuring that the best spots are selected for the wind plants location, resulting in higher power output and, consequently, in lower LCOE. Although the O\&M costs are the least influent ones, they should not be overlooked as they can represent more than $30 \%$ of the total cost. Wind availability is uncertain and this factor has a high influence on the LCOE production from wind generators. Probabilistic calculations for LCOE for wind power show a variation between $-54 \%$ and $+104 \%$ comparatively to the deterministic value. The LCOE of wind can be reduced by the upgraded performance of wind turbines, as well as their location in higher wind speed locations, that help improve the average capacity factor.

Figure 5 represents the obtained PDF function for the LCOE for solar PV, combining the risk effect on investment cost, O\&M costs and load factor, as well as the tornado chart for the probabilistic sensitivity analysis. 

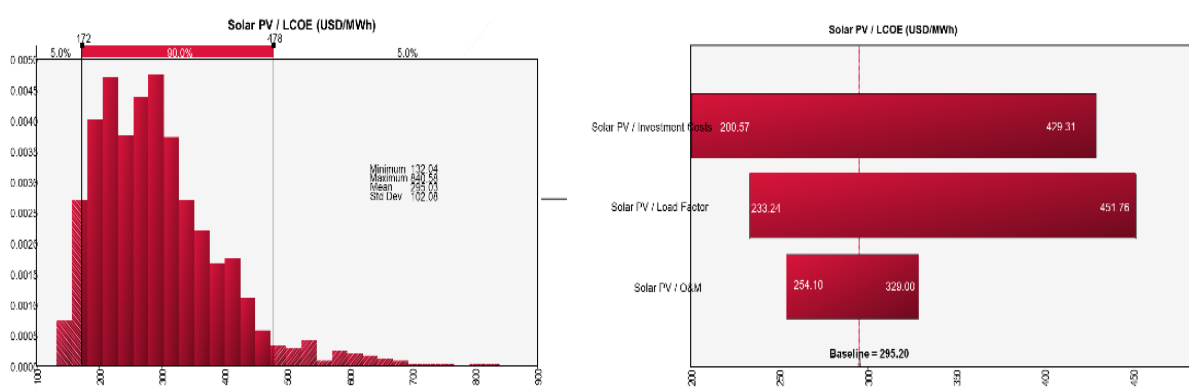

Fig. 5. Probability distribution function (left) and tornado chart (right) for LCOE solar PV.

From the deterministic analysis, LCOE for solar power should be slightly less than $282 \mathrm{USD} / \mathrm{MWh}$ (236 €/MWh, according to average exchange rate in March 2015, from www.bportugal.pt consulted in April 2016). Figure 5 shows that the probability of reaching a value higher than that is more than $30 \%$ and the average FIT for large PV power plants was until recently between 310-317 €/MWh (data obtained from www.dgeg.pt consulted in April 2016). The values show a more stable regime for solar power than for wind power with most the probabilistic LCOE values being lower than the deterministic one. The probability of reaching a LCOE value lower than the FIT is more than $60 \%$. The tornado chart (Figure 5) shows that in the case of solar PV the investment cost is also what influence the most the final value of the LCOE. The impact of the load factor is also highly relevant, as well as the O\&M costs. System technology and design can also affect LCOE, for the similar systems in the same location may produce very different financial results. Probabilistic calculations for LCOE for PV power show a variation between $-51 \%$ and $+196 \%$ comparatively to the deterministic value. Although this interval is larger than the one obtained for wind power, the values seem to be more concentrated on the left side of the PDF resulting in a higher positive skew. The costs and financial returns of solar PV systems should be calculated by taking into account factors such as levels of solar insolation, government and utility incentives, and the cost of grid produced electricity, for they vary based on location. Location is not the only relevant parameter, but also the size, supplier and geographical attributes of the PV system can influence the prices of electricity. As costs of solar PV systems drop, in more and more locations, these become more cost-effective from the experience curve. To estimate if the installation of a solar PV system is profitable in a particular location, then a gathering of detailed information about the place in question, about incentives, grid produced electricity rates and levels of solar must be made [12].

\section{Conclusion}

The decision-making process to invest on the best projects for electricity production and for selecting the technology and resources is strongly driven by the economic factors and the use of methods relying on the LCOE can bring important information. LCOE allows to compare different power plants with different technical characteristics and cost structures. In this study, two renewable technologies have been selected and 
for each one the LCOE was calculated assuming the Portuguese climatic conditions. Initially, a deterministic analysis was conducted allowing computing the expected LCOE for both technologies. Afterwards, a probabilistic risk assessment was undertaken aiming to compute the PDF of the LCOE for both technologies. The results showed the high cost to implement and deploy RES, and in most cases higher than the FIT established for Portugal. This represents an important drawback for investors, as if those cannot have some guarantees of properly rewarding their investments, then they will be reluctant to participate in these projects, regardless of the environmental benefits. For the case of wind power, LCOE showed to be much behind the FIT offered in Portugal being highly affected by the high cost and also by the variability of the load factor. As for solar PV, although the range of values is higher, the LCOE tends to concentrate on the left side of the PDF showing a higher probability of FIT to compensate the LCOE. Given the low availability of data, the results obtained should be looked with caution. However, the major contribution of this paper to the literature is the proposed method for the definition of a probabilistic LCOE, especially well-suited for RES project characterized by high uncertainty of the resources and also by the still expected relevant technological development.

\section{Acknowledgments}

This work has been supported by COMPETE: POCI-01-0145-FEDER-007043 and FCT Fundação para a Ciência e Tecnologia within the Project Scope: UID/CEC/00319/2013.

\section{References}

1. EIA, 2017. International Energy Outlook 2017, Report Number: DOE/EIA-0484.

2. European Commission, 2017. "Directive of the European Parliament and of the Council on the promotion of the use of energy from renewable sources", European Commission, Brussels.

3. Branker K., Pathak M.J.M., Pearce J.M., 2011. A review of solar photovoltaic levelized cost of electricity. Renewable and Sustainable Energy Reviews, 15, 4470-4482.

4. Edenhofer O., Hirth L., Knopf B., Pahle M., Schlomer S., Schimd E., Ueckerdt F., 2013. On the economics of renewable energy sources. Energy Economics, 40, S12-S23.

5. Matos, E. Monteiro, T., Ferreira, P., Cunha, J., García-Rubio, R. 2015. "An optimization approach to select portfolios of electricity generation projects with renewable energies" Applied Mathematics \& Information Sciences, 9(2L), 1-7.

6. Larsson S., Fantazzini D., Davidsson S., Kullander S., Hook M., 2013. Reviewing electricity production cost assessments.

7. Hernández-Moro J., Martínez-Duart J.M., 2012. Analytical model for solar PV and CSP electricity costs: Present LCOE values and their future evolution. Renewable and Sustainable Energy Reviews, 20, 119-132.

8. Ueckerdt F., Hirth L., Luderer G., Edenhofer O., 2013. System LCOE: What are the costs of variable renewables. Energy, 63, 61-75.

9. NEA, 2015. Projected Costs of Generating Electricity, NEA No. 7057, OECD Publications, Paris.

10. DGEG, 2005. Renovaveis - estatísticas rápidas - Dezembro 2005 (www.dge.pt)

11. DGEG, 2015. Renovaveis - estatísticas rápidas - Abril 2015 (www.dge.pt)

12. Peters M., Schmidt T.S., Wiederkehr D., Schneider M., 2011. Shedding light on solar technologies - A techno-economic assessment and its policy implications. Energy Policy, 39, 6422-6439. 